\title{
Improving the Prevention of Environmental Risks with Convertible Bonds*
}

\author{
André SCHMITT ${ }^{\dagger} \quad$ Sandrine SPAETER ${ }^{\ddagger}$
}

May, 2002

${ }^{*}$ We wish to thank our colleagues at BETA and at LARGE from Louis Pasteur University of Strasbourg and at GERME from ESA-Lille 2 University, and participants at the LABORES Seminar, Université Catholique de Lille, at the SCSE 2001 Conference in Quebec, at AFFI 2001 Conference in Namur, at EFMA 2001 Conference in Lugano, and at the 28th Seminar of the European Group of Risk and Insurance Economists in Strasbourg for helpful comments on earlier versions. In particular we thank Nancy Bergeron, Patrick Cohendet, Georges Dionne, Isabelle Girerd-Potin, Frédéric Herbin, Michel A. Robe and Patrick Roger for insightful comments and discussions. The IFE (Institut Français de l'Energie) is aknowledged for financial support.

†GERME, ESA-Université Lille 2, 1, Place Déliot, F-59 000 LILLE, Phone: +33 (0)3 20907479. Fax: +33 (0)3 209077 03. E-mail: aschmitt@hp-sc.univ-lille2.fr

${ }^{\ddagger}$ Corresponding author. BETA, Université Louis Pasteur, 61, Avenue de la Forêt Noire, F-67 085 Strasbourg Cedex, Phone: +33 (0)3 902420 76. Fax: +33 (0)39024 20 71. E-mail: spaeter@cournot.ustrasbg.fr 
Résumé : Dans cet article, un manager emprunte des fonds à une banque pour les investir dans une activité de production risquée pour l'environnement. Il peut décider de mesures préventives qui diminueront ce risque, mesures non observables par les opérateurs extérieurs à la firme. De plus, le manager est protégé par la règle de la responsabilité limitée. Dans ce contexte d'actions cachées, nous montrons que l'émission d'obligations convertibles - qui donnent le droit à leur détenteur d'échanger de la dette contre des actions, peut améliorer les incitations de la firme à investir en prévention par rapport à ce que permet un contrat de dette standard. Ce type de relation entre la firme et la banque peut être considéré comme une alternative, ou un complément, à une législation environnementale du type de CERCLA, qui prévaut aux Etats-Unis et qui permet d'étendre la responsabilité financière d'un sinistre à tout opérateur de la firme polluante (une banque par exemple). Nos résultats pourraient ainsi servir de support de réflexion à l'élaboration d'une législation environnementale européenne qui, d'après les discussions entre pays membres de l'Union, se devrait d'être plus stricte que l'actuelle législation. Nous obtenons un contrat avec émission d'obligations convertibles quin génère plus d'incitations en matière de prévention que de la dette standard, plus de revenu espéré pour la firme et un niveau de bien-être social espéré plus élevé. Les implications économiques de nos résultats sont largement discutés. Mots-clé : Risque moral, risque environnemental, prévention, obligation convertible. Classification JEL : Q29, D82, G32.

Abstract: In this paper, a manager borrows external funds in order to invest in production and also in prevention. The latter action must reduce the environmental risk driven by the activity of the firm. Prevention is observable neither by outside lenders nor by institutions such as environmental agencies for instance. In such a situation, we show that issuing convertible bonds - which permits the holder to exchange his bonds for a predetermined number of shares of the firm - from a limited liability firm could be a way to improve prevention compared to what can usually be done with standard debt. Such a relationship between the firm and the bank might be an alternative, or a complement, to the CERCLA legislation about extended liability which prevails in the United States and which is often discussed in Europe as a possible support of a more tightened European environmental legislation. We obtain an optimal convertible bond contract that induces more prevention and higher expected net revenues for the firm than standard debt. The expected social welfare is also improved. Finally, the economic implications of our findings are discussed. Key Words: Moral Hazard, Environmental Risk, Limited Liability, Prevention, Convertible Bond. JEL Classification: Q29, D82, G32. 


\section{Introduction}

Consider a manager of a firm who privately decides preventive measures in order to reduce the environmental risk driven by his activity; he can hide the chosen level of prevention to outside lenders. This moral hazard problem is exacerbated if the firm is protected by the limited liability ule $^{1}$ : the manager is not aware by damages that would be larger than the firm's net value. In this context, the manager has no incentive to adopt the required level of prevention, namely the level that maximizes the expected social welfare, or that asked by a bank or an insurance company (Pitchford (1995), Boyer and Laffont (1997)). Hence, it is necessary to find some incentive and/or regulatory rules that would induce better prevention.

In that spirit, the legislation CERCLA (Comprehensive Environmental Response, Compensation and Liability Act, 1980-1985) was adopted by the Congress of the United States. In case of bankruptcy of the guilty firm, it allows the Environmental Protection Agency (EPA) to prosecute any operator sufficiently involved in the decisions of the pollutant firm - whatever its size, such as banks, in order to recover the money engaged for the clean-up of polluted sites and for the victims' compensation ${ }^{2}$. It was expected that banks enforce firms to take adequate preventive actions, through the supply of suitable financial contracts. Moreover, CERCLA made it possible to get more available funds for clean-up and compensation.

For several years, the European Commission works on the possibility of adopting an environmental legislation which content would be inspired by the CERCLA legislation ${ }^{3}$. Besides, the Commission is interested in the financial guarantees that are or should be imposed on firms before starting an activity that presents a risk for the environment ${ }^{4}$.

\footnotetext{
${ }^{1}$ Ex ante the manager is fully responsible for the environmental damage but, ex post, he is held financially liable only up to the firm's net value.

${ }^{2}$ For details about this legislation, see Boyer and Laffont (1996) and Anderson (1998).

${ }^{3}$ See the 1998 working paper of the European Environmental Bureau "Environmental liability in Europe: Concerning the need for a European Directive on environmental liability".

${ }^{4}$ See the 1997 Report to the European Commission by DELPHI International LTD in Association with Ecologic GMBH.
} 
Several public or private funds dedicated to the compensation of victims already exist; they are financed by the oil industry for oil spills, by the steel sector for water pollution or by governments. Nevertheless, even with those funds - which cost should be rather fair because of the small frequency of very high damages (Smets, 1992) -, compensation and clean-up are often not complete. Such compensation funds should be used only for damages exceeding the insured level, if insurance has been bought, or for damages that are not covered at all. But legal procedures are long and complex and in most cases the value of compensation decided by the legal court or by experts is significantly less than the evaluation made by the victims.

CERCLA seems to be able to solve both ex ante and ex post problems: it should lead to better prevention and to better compensation in case of a damage. Nevertheless, several studies show that extended liability as thought by CERCLA might not be a good solution when information is not perfect between the firm and its operators. Extended liability may increase the cost of borrowing and this may lead to less prevention from the firm and to underinvestment in positively valued projects (Pitchford (1995), Boyer and Laffont (1997)). Beard (1990), Lipowsky-Posey (1993) and Dionne and Spaeter (2002) obtain more mitigate results. But one important feature is that extended liability always deteriorates the solvency of the firm.

Finally, limited liability and moral hazard do not facilitate the implementation of adequate prevention as desired by CERCLA. In this paper, we propose an alternative solution by focusing on a more active position of the bank in its relation with the firm it finances. We show that it is possible to get more prevention and better expected social welfare, without a deterioration of the financial condition of the firm by considering convertible bonds instead of standard debt, often used in this literature.

A convertible bond is a bond with the added feature that its holder has the option to turn the bond back to the firm in exchange for a specified number of shares of the firm. It is well known that this claim can mitigate the incentives to take risk and reduce the agency costs between bondholders and stockholders (see Barnea, Haugen and Senbet (1980), Green (1984)). Other studies have shown that the issue of convertible bonds is 
well adapted when it is difficult to estimate asset risk (Brennan and Schwartz (1988)) or when high asymmetric information makes a stock issue unattractive (Stein (1992)). Indeed, empirical evidence shows that American companies issuing convertible bonds are riskier than companies issuing straight debt (Lewis, Rogalski and Steward (1999)). In this paper, we show how this conversion feature may enhance environmental protection by mitigating the distortionary effects on prevention induced by limited liability and $e x$ ante moral hazard. If the conversion option remains unexercised, the cash redemption is lower than the one of a standard debt contract. Hence, the firm internalizes more expected marginal benefit of prevention and he has incentives to increase the level of prevention. On the other hand, if the bank exercises its option, the firm has to share profits in good states of nature, that is for low levels of environmental damages. This characteristic may induce less prevention since the firm is less concerned by these states. In fact, we show that there is an optimal contract that induces a positive net effect on prevention and that also mitigates the negative impact on the firm's solvency, which appears in the standard debt model with extended liability. Moreover we show that this contract, which is optimal for the firm, also improves the expected social welfare. In the last section of the paper, we link the usefulness of such findings to the implementation of a European legislation inspired by CERCLA: In which manner, a bank having financed a firm with convertible bonds could benefit from less severe court decisions in case of an environmental damage ? For instance, since convertible bonds may induce more prevention, the underwriting of these securities could be positively interpreted by a legal court in charge of recovering clean-up and compensation funds.

Besides the environmental dimension we give to this problem of financial contract, another originality of our work lies in the comparison of standard debt with convertible debt. Indeed, most of the empirical studies that focus on the motivations of issuers (Essig (1991), Hoffmeister (1977), Stein (1992)) show that convertible bonds are often issued as an alternative to the issuing of common stocks and very seldom as an alternative to classical bonds. It is often argued that such a behavior might send a good signal to the market when information is asymmetric between buyers and sellers: holders of 
convertible bonds may benefit from good results of the firm by exercising the conversion option and they are also protected against bad results since they do not loose more than the face value of debt. In our model, the environmental component of the firms' activities may create a new motivation for issuing convertible bonds.

The paper is organized as follows. Section 2 briefly presents the existing results obtained with standard debt and extended liability. They are used as a benchmark in Section 3 where the effects of issuing convertible bonds on prevention are investigated. Section 4 presents some comparative statics and focuses on the solvency of the firm and on the social welfare. (In Appendix 6 we compute a parametrized example that illustrates our results.) Section 5 concludes the paper with a discussion on the economic implications of our results. In particular, we discuss some characteristics of convertible bonds, not considered in the model, such as callable bonds or sequential conversion for instance.

\section{Standard Debt and Extended Liability}

We recall the most interesting results obtained with standard debt. They will be compared in the next section with those related to convertible bonds.

Consider a firm which needs some external funds in order to start its activity. This activity yields a random positive profit denoted $(X-\widetilde{y})$, with $X$ a positive scalar and $\widetilde{y}$ an environmental risk with realizations in the bounded positive interval $[0, T]$. The firm can make prevention to reduce this risk. Let $F(y / e)$ denote the conditional distribution of $\widetilde{y}$, where $e$ is the level of prevention defined on $[0, \bar{e}]$, with $\bar{e}>0$. The associated density function is $f(y / e)$. It is reasonable to assume that $F$ displays the first order stochastic dominance property and is convex in prevention: this implies that $F_{e}(y / e) \geq 0$, $F_{e e}(y / e) \leq 0$ and $F_{e}(0 / e)=F_{e}(T / e)=0$. Total investment equals the owner-manager's equity $E$ plus the funds $B$ borrowed from a bank. Besides, prevention is considered as a non monetary effort ${ }^{5}$ which opportunity cost $\phi(e)$ satisfies $\phi^{\prime}(e)>0$ and $\phi^{\prime \prime}(e)>0$.

\footnotetext{
${ }^{5}$ For a model where $e$ is financed out of the borrowed funds, see Dionne and Spaeter (2002).
} 
In this section we assume that a standard debt contract ${ }^{6}$ is signed between the bank and the owner-manager of the firm. The face value of debt is $D$, with $D \equiv D(B, E){ }^{7}$ Besides, we have $e \equiv e(D)$; the level of prevention chosen by the firm is affected by the cost of borrowing.

The profit $X-y$ is common knowledge - it can be publicly announced by a court, but the level of prevention $e$ is not observable by the bank: we have to cope with an ex ante moral hazard problem. If the environmental damage is very large the firm's assets may not be sufficient for compensation and clean-up and the firm is pushed into bankruptcy. We also assume that the firm is always solvent when no damage occurs. Formally, this means that the maximum possible profit $X$ is less than $T$, but larger than $D$. This last assumption permits us to isolate the impact of the environmental risk on the firm's behavior.

Both the bank and the owner-manager are risk-neutral ${ }^{8}$. Thus it is possible to analyze the willingness of the manager to pay for prevention because of financial incentives and not because of his attitude towards risk. Moreover the firm is protected by the limited liability rule: the manager is responsible ex ante for the total amount of damage he can create but, ex post, compensation and clean-up costs he pays cannot be higher than the firm's net value. Formally, there exists a level of damage $\widehat{y}$ in $] 0, T[$ such that the net revenue $r(y)$ of the manager, equal to the profit minus the cost of borrowing, is nil for any damage equal to or higher than $\widehat{y}: r(y)=X-y-D>0$ if $y<\widehat{y}$, and zero otherwise. Thus $\widehat{y} \equiv \widehat{y}(D)$ and the firm's probability of bankruptcy is $1-F(\widehat{y}(D) / e)$.

\footnotetext{
${ }^{6}$ Cf. Innes (1990), Dionne and Viala (1994), Chiesa(1992) or, more recently, Coestier(2000) for an analysis of the optimal capital structure under moral hazard.

${ }^{7}$ The level of equity $E$ is fixed at its optimal value at the beginning of the activity, knowing that a standard debt contract is signed. Consequently, with $E$ constant we can normalize its opportunity cost to zero. The optimal structure has been addressed in a different context by Calcagno (2001), who considers moral hazard between a manager (the agent), in charge of the production process, and an inside shareholder (the principal).

${ }^{8}$ Actually, Sappington (1983) shows that considering limited liability of a risk-neutral agent is such as having to deal with a risk averse individual since all the risk cannot be transferred to him at optimum.
} 
Due to the environmental legislation, the bank is reimbursed by the firm only after victims have been compensated in case of an environmental damage. Moreover, the financial contracts offered by the bank to the firm must yield an expected net revenue equal to what it would have obtained by buying risk-free assets for an amount $B$. Hence, the participation constraint of the bank is

$$
B(1+i)=D F(\widehat{y}(D) / e)+\int_{\widehat{y}}^{X+l}(X-y) f(y / e) d y-l(1-F(X+l / e)),
$$

where $i$ is the risk-free interest rate and $l$ the level of extended liability. If $l$ is equal to zero (to $T-X)$, no (full) responsibility is extended to the bank. For any level between 0 and $T-X$ the bank's liability is only partial.

Finally, the decision timing is as follows. The firm asks for external funds $B$ to the bank, which decides the level of face value $D$ the firm will have to reimburse. Then the manager chooses the level of prevention $e$ that maximizes his expected net revenue. At the end of the period, the environmental risk is realized and profits are observed. Formally, the owner-manager maximizes his expected net revenue given by

$$
R=\int_{0}^{\widehat{y}(D)}(X-y-D) f(y / e) d y-\phi(e)
$$

with respect to $e$ and subject to (1). We denote $e^{P}$ the optimal solution to this program.

If information would be perfect, a regulator would define $e^{S}$ as the level of prevention that maximizes the expected social welfare. It is equal to the expected net revenue of the manager, minus the expected net loss of the victims, knowing that the expected net profit of the bank is nil ${ }^{9}$. Taking into account the zero net profit constraint of the bank,

\footnotetext{
${ }^{9}$ This gives$$
W^{S}=R-\int_{X+l}^{T} y f(y / e) d y+X(1-F(X+l / e)) .
$$ 
the expected social welfare, after simplification, is defined by:

$$
W^{S}=\int_{0}^{T}(X-y) f(y / e) d y-B(1+i)-\phi(e) .
$$

Lemma 1 hereafter summarizes the respective first order conditions.

Lemma 1 The optimal private level of prevention $e^{P}$ satisfies the first order condition $\int_{0}^{\widehat{y}(D)} F_{e}\left(y / e^{P}\right) d y=\phi^{\prime}\left(e^{P}\right)$, while the optimal social level of prevention $e^{S}$ satisfies $\int_{0}^{T} F_{e}\left(y / e^{S}\right) d y=\phi^{\prime}\left(e^{S}\right)$

Proof. See Appendix 1. Both second order conditions are satisfied.

In both expressions in Lemma 1, the left-hand-side term is the expected marginal benefit of prevention and the right-hand-side term is the expected marginal cost. Notice that the full internalization of the marginal benefit in the social case is reflected by the integration on the whole interval $[0, T]$, while partial internalization of this effect in the private case explains why it is only evaluated on the states of nature relevant for the firm, namely on $[0, \widehat{y}]$. While the marginal cost remains identical in both cases partial private internalization yields a lower private expected marginal benefit of prevention. This means that prevention becomes relatively more expensive for the manager than for the regulator and, consequently, he will choose a private level of prevention lower than the socially optimal one.

As discussed in the introduction, when the legislation CERCLA was adopted by the American congress, the objective was to induce more preventive behaviors for firms, knowing that limited liability creates some distortionary effects ${ }^{10}$. Nevertheless, the existing conclusions about the theoretical effects of extended liability on prevention are mitigated (Beard (1990), Lipowsky-Posey (1993), Pitchford (1995), Boyer and Laffont (1997), Gobert and Poitevin (1998), Dionne and Spaeter (2002)). In our simple model,

\footnotetext{
${ }^{10}$ Recall that limited liability induces only partial internalization of the environmental risk by firms. Thus prevention of those risks becomes less worthy for them.
} 
we obtain that extended liability under moral hazard always yields a lower level of prevention than that we would obtain without CERCLA. Actually, when the bank becomes potentially liable, it transfers part of this additional cost to the firm by increasing the face value of debt. This increase in the cost of borrowing implies that the firm invests less in prevention. We also obtain that extended liability associated with standard debt always leads to a deterioration in the financial situation of the firm. All these results are developed in Appendix 2.

In the following section we show how issuing convertible bonds may mitigate these negative effects.

\section{Convertible Bonds and Prevention}

First we present the model. Second we show that it exists convertible bond contracts ( $\mathrm{CB}$ contracts in the course of the text) that improve the prevention level compared to standard debt. Lastly we characterize the contracts, among those offered by the bank, that lead to more prevention and to more expected net revenue for the firm.

\subsection{The Model}

Instead of standard debt, assume the firm decides to issue $b$ convertible bonds for a total face value equal to $D^{C}$. Because holders of convertible bonds gain the upside potential of common stocks while actually holding a less risky asset, $D^{C}$ has to be lower than $D$. Otherwise, the owner-manager will never have an interest in issuing these assets. Condition $D^{C}<D$ may be considered as a participation constraint of the firm. Still assume that there is only one bondholder, namely the bank, and that each convertible bond can be exchanged for $n$ shares. ${ }^{11}$

\footnotetext{
${ }^{11}$ Our principal aim is to compare straight debt with convertible bonds, rather than looking at the optimal capital structure. For such a discussion, we refer to Robe (1999 and 2002) who shows that convertible securities are a key component of the optimal capital structure when the agent (here the manager) is risk averse (Robe (1999)) or, alternatively, when limited liability holds (Robe (2002)) such
} 
The manager holds $m$ initially outstanding shares. They correspond to $E$, defined as the owner-manager's equity in the previous section. The bank will exercise its option if this action is more profitable than not exercising ${ }^{12}$ that is, if the percentage of profits it receives in this case is higher than the face value of debt:

$$
\left(\frac{b n}{m+b n}\right)(X-y)>D^{C}
$$

The manager receives the remaining revenue $\left(1-\frac{b n}{m+b n}\right)(X-y)$, which is lower than $X-y-D^{C}$ because of (4). Consequently, the net revenue function of the manager can be written:

$$
r^{C}(y)=\operatorname{Max}\left\{\operatorname{Min}\left\{\left(1-\frac{b n}{m+b n}\right)(X-y) ; X-y-D^{C}\right\} ; 0\right\}
$$

If the level $y$ of the environmental damage pushes the firm into bankruptcy, the bank will not exercise its option and the net revenue of the manager is zero because of the limited liability rule. Conversely, we assume that it is profitable for the bank to exercise if no damage occurs ${ }^{13}$. Since $r^{C}$ is continuous in $y$, there exists a level $y^{C}$ of damage such that it is profitable for the bank to exercise if $y<y^{C}$ and it should not leave its initial position if $y \geq y^{C}$, with $\left.y^{C} \in\right] 0, T$. If we use the notation $\frac{b n}{m+b n}=a$ with $^{14} a \equiv a\left(D^{C}\right)$, at point $y^{C}$ we have:

$$
a\left(X-y^{C}\right)=D^{C}
$$

Figure 1 displays such a contract. We also represent the standard debt contract with face value $D$, where $\widehat{y}$ is the minimum level of damage that induces bankruptcy with this contract.

as in our model.

${ }^{12}$ In our one-period model, the bank is constrained to convert the bonds as one block. We discuss this assumption and the possibility of sequential conversion in the last section of the paper.

${ }^{13}$ Otherwise, the basic economic problem stressed in this paper vanishes.

${ }^{14}$ The number of convertible bonds that are issued is affected by the face value of debt. Actually, the higher is $D^{C}$, the lower $a: a^{\prime}\left(D^{C}\right)<0$. This result can be obtained thanks to a total differentiation of the participation constraint (8) of the bank. 
Figure 1 about here

We denote $\widehat{y}^{C}$ the level of damage that induces bankruptcy with a CB contract:

$$
X-D^{C}-\widehat{y}^{C}=0
$$

Since $D^{C}<D$, we also have $\widehat{y}^{C}>\widehat{y}$. The crossing point $A$ on Figure 1 reflects the participation constraint of the bank. It will accept to participate if the diminution of its net revenue in the states of nature where it does not exercise, compared to the standard debt contract case, is at least compensated by a larger revenue in the states where it exercises. Hence for $y=0$, we must have $a X>D$, and this implies that $r^{C}(0)<X-D$ with $r^{C}(0)=(1-a) X$.

Finally, the manager has to decide which convertible bond contract $\left(a, D^{C}\right)$ and which level of prevention $e$ maximize his expected net revenue knowing that the risk-neutral bank offers contracts that satisfy its participation constraint. Formally, the optimization program states as follows:

$$
\max _{D^{C}, e} R^{C}=(1-a) \int_{0}^{y^{C}}(X-y) f(y / e) d y+\int_{y^{C}}^{\widehat{y}^{C}}\left(X-y-D^{C}\right) f(y / e) d y-\phi(e)
$$

subject to

$$
\begin{aligned}
B(1+i)= & a \int_{0}^{y^{C}}(X-y) f(y / e) d y+D^{C}\left(F\left(\widehat{y}^{C} / e\right)-F\left(y^{C} / e\right)\right) \\
& +\int_{\widehat{y}^{C}}^{X}(X-y) f(y / e) d y
\end{aligned}
$$

Green (1984) shows that issuing warrants instead of standard debt induces a less risky behavior from the manager. He has incentives to select less risky projects because profits in good states of nature will be shared with the new stockholder after exercise, while bad states of nature still lead to zero revenue for him because of the limited liability 
rule: high profits, possible with risky projects, are less attractive. Since the properties of convertible bonds are similar to those of warrants ${ }^{15}$, we should obtain this incentive effect with convertible bonds. In fact, two opposite effects on prevention appear.

\subsection{Impact on Prevention}

Program (7)-(8) is divided in two steps. First, the firm evaluates the optimal preventive strategy for each financial contract proposed by the bank, including standard debt. The bank cannot observe the chosen strategy, so that it cannot build a contract contingent on the level of prevention. Nevertheless, since it knows the distribution of the environmental risk, it is able to take the strategy of the firm into account when choosing which financial contract it will propose to the manager. Hence the bank knows that a given contract $\left(a, D^{C}\right)$ will induce a strategy $e^{*}\left(a, D^{C}\right)$ from the firm. Thus it must list the contracts $\left(a, D^{C}\right)$ that satisfy its participation constraint, knowing the forthcoming behavior of the firm. Finally, the manager observes these contracts and chooses the one that maximizes his expected net revenue. More formally, the firm seeks the optimal path $e^{*}$ for each contract $\left(a, D^{C}\right)$ with $a \equiv a\left(D^{C}\right)$ between 0 and 1: We obtain a function $e^{*}\left(D^{C}\right)$. Then $e^{*}\left(D^{C}\right)$ is substituted in Program (7)-(8), which is solved with respect to $D^{C}$ this time: Which financial contract, among those offered by the bank, maximizes the manager's expected net revenue knowing his forthcoming optimal preventive decision $e^{*}\left(D^{C}\right)$ ?

Lemma 2 The private optimal function of prevention $e^{*}\left(D^{C}\right)$ satisfies the following first order condition

$$
(1-a) \int_{0}^{y^{C}} F_{e}\left(y / e^{*}\right) d y+\int_{y^{C}}^{\widehat{y}^{C}} F_{e}\left(y / e^{*}\right) d y=\phi^{\prime}\left(e^{*}\right),
$$

for any given financial contract $\left(a, D^{C}\right)$.

Proof. See Appendix 3.

\footnotetext{
${ }^{15} \mathrm{~A}$ convertible bond contract gives the right to the holder to exchange bonds for shares, while warrants permit him to buy new shares at a predetermined price.
} 
The second order conditions are also satisfied. Two effects appear explicitly in (9). On the one hand, when the bank purchases convertible bonds, it has to pay for the conversion option, compared to classical bonds, and this feature leads to a reduction in the cost of borrowing paid by the firm. Consequently, this improves the financial condition of the firm, decreases the probability of bankruptcy and induces more private internalization of the expected marginal benefit of prevention: Now, it is evaluated on $\left[0, \widehat{y}^{C}\right]$ instead of $[0, \widehat{y}]$. On the other hand, the fact that the firm has to share the highest levels of profits with the bank, if it exercises, makes these good states relatively less attractive to the firm and prevention, done in order to increase the chances to be in those states, becomes less valuable. Hence this second (negative) effect on prevention may counterbalance the first one. Both effects appear on Figure 1 ; The fact that, on $\left[X-\widehat{y}^{C}, X-y^{C}\right]$, the firm's net revenue in the $\mathrm{CB}$ case is higher than the one obtained when standard debt is issued reflects the positive impact of convertible bonds on prevention. The negative effect on prevention explains the reduction in the shape of the firm's expected net revenue on $\left[X-y^{C}, X\right]$ compared to the standard debt case, where the shape equals one. In Proposition 1 hereafter, we show that there exists a set of $\mathrm{CB}$ contracts inducing a positive net effect on prevention.

Proposition 1 There exists a level of face value $\overline{D^{C}}$ strictly less than $D$ such that, for any convertible bond contract with face value in $\left[\overline{D^{C}}, D[\right.$, the firm has sufficient incentives to do more prevention than with a standard debt contract.

\section{Proof. See Appendix 4.}

Each $\mathrm{CB}$ contract in $\left[\overline{D^{C}}, D[\right.$ mitigates the distortionary effects on prevention induced by limited liability and ex ante moral hazard. Proposition 1 also implies that the bank should not be too much involved in the activity of the firm. Indeed, with $a$ increasing when $D^{C}$ decreases, the bank should not own a large percentage of the capital after having exchanged its bonds for shares. In this manner the manager has not to share too much of the profits in the good states of nature and he keeps incentives to do prevention. Still notice that empirical observations suggest that firms, when issu- 
ing convertible debt, are reluctant to dilute stockholders' ownership. For instance, the french legislation allows current stockholders to have priority to underwrite new issues of convertible bonds up to an amount which would keep the capital structure unchanged if these bonds were converted.

Until now, we have focused on the conditions that are sufficient for observing more prevention. But even if those contracts exist, we must be sure that they are accepted by the bank. We must also be sure that one of them is chosen by the firm. In other words, we have to answer the following question : among the contracts in $\left[\overline{D^{C}}, D[\right.$, does there exist one that maximizes the expected net revenue of the firm and is offered by the bank ? The properties of the contract(s) preferred by the firm are summarized in Lemma 3 hereafter.

Lemma 3 Assume that $R^{C}$ is concave in $D^{C}$. The contract $\left(a\left(D^{C *}\right), D^{C *}\right)$ that maximizes the expected net revenue of the firm is such that:

i) With $\frac{d R^{C}}{d D^{C}}=-a^{\prime}\left(D^{C}\right) \int_{0}^{y^{C}}(X-y) f\left(y / e^{*}\right) d y-\left(F\left(\widehat{y}^{C} / e^{*}\right)-F\left(y^{C} / e^{*}\right)\right), D^{C *}$ belongs to $] 0, D\left[\right.$ if $\frac{d R^{C}}{d D^{C}}$ is nil and equals zero if this ratio, evaluated at $D^{C *}=0$, is negative.

ii) Straight debt is never optimal.

Proof. Point i) corresponds to a standard discussion on the first order conditions when the solution must belong to a bounded interval. $\frac{d R^{C}}{d D^{C}}$ is obtained by computing $R_{e}^{C} \cdot \frac{d e}{d D^{C}}+R_{D^{C}}^{C}+R_{a}^{C} \cdot a^{\prime}\left(D^{C}\right)+R_{\widehat{y}^{C}}^{C} \cdot \widehat{y}_{D^{C}}^{C}+R_{y^{C}}^{C} \cdot y_{D^{C}}^{C}$ with $R^{C}$ defined by $(7), R_{e}^{C}$ equal to zero at optimum and $R_{\widehat{y}^{C}}^{C}$ equal to zero by definition of $\widehat{y}^{C}$. The concavity of $R^{C}$ with respect to $D^{C}$ is not a well established result in our model. But, $R^{C}$ is a concave function of $e$, which is a function of $D^{C}$. From the combination of functions, we can conclude that $e^{*}$ concave in $D^{C}$ leads to $R^{C}$ concave in $D^{C}$. Although we are not able to show that $e^{*}$ is concave in $D^{C}$, we have shown that $\frac{d e}{d D^{C}}$ equals zero at $D^{C}=\overline{D^{C}}$, with $\overline{D^{C}}$ in $] 0, D$ [, is decreasing between $\overline{D^{C}}$ and $D$ and its slope at $D^{C}=0$ is strictly positive. Under these properties, it is not unreasonable to assume that $e$ displays a unique maximum, which is $\overline{D^{C}}$ and, consequently, that this property is also met for $R^{C}$, since $R^{C}$ is concave in $e$. Point ii) is obtained by noticing that $D^{C *}=D$ if $\left.\frac{d R^{C}}{d D^{C}}\right|_{D^{C *}=D} \geq 0$. 
But $\frac{d R^{C}}{d D^{C}}(D)=-F\left(\widehat{y} / e^{*}\right)$ : it is always negative, so that standard debt is never an optimum.

Lemma 4 hereafter is useful to analyze the contracts proposed by the bank.

Lemma 4 The $C B$ contracts that satisfy the participation constraint of the bank, knowing the optimal strategy of the firm $e^{*}\left(D^{C}\right)$, are such that:

$$
-\frac{d R^{C}}{d D^{C}}+\left[a\left(D^{C}\right) \int_{0}^{y^{C}} F_{e}\left(y / e^{*}\right) d y+\int_{\widehat{y}^{C}}^{X} F_{e}\left(y / e^{*}\right) d y\right] \frac{d e}{d D^{C}}=0,
$$

with $\frac{d R^{C}}{d D^{C}}$ defined in Point i) of Lemma 3.

Proof. Equation (10) is obtained by differentiating the participation constraint (8) of the bank with respect to $D^{C}$. This variation rate must be nil for any contract $\left(a, D^{C}\right)$, knowing $e^{*}\left(D^{C}\right)$ :

$$
\begin{aligned}
& a^{\prime}\left(D^{C}\right) \int_{0}^{y^{C}}(X-y) f\left(y / e^{*}\right) d y+\left(F\left(\widehat{y}^{C} / e^{*}\right)-F\left(y^{C} / e^{*}\right)\right) \\
& +\left[a \int_{0}^{y^{C}} F_{e}\left(y / e^{*}\right) d y+\int_{\widehat{y}^{C}}^{X} F_{e}\left(y / e^{*}\right) d y\right] \frac{d e}{d D^{C}}=0
\end{aligned}
$$

By noticing that the first term of the left-hand-side in (11) is minus $\frac{d R^{C}}{d D^{C}}$ defined in Lemma 3, Lemma 4 is demonstrated.

Finally, by considering simultaneously Lemmas 3 and 4 , and by focusing only on prevention-improving contracts - those with face value in $\left[\overline{D^{C}}, D\right]$-, we are able to propose the following discussion. The term into brackets in (10) is always positive, so that $D^{C *}$ must be such that a variation in its neighborhood induces the same kind of effect on the firm's expected net revenue and on its preventive strategy: $\frac{d R^{C}}{d D^{C}}$ and $\frac{d e}{d D^{C}}$ must have the same sign. Knowing that $\frac{d e}{d D^{C}}$ is negative for the CB contracts we are interested in, we conclude that the contracts proposed by the bank are such that $\frac{d R^{C}}{d D^{C}}$ 
is negative or nil. With $R^{C}$ concave in $D^{C}$ by assumption, we deduce from Point i) of Lemma 3 that the firm will choose the $\mathrm{CB}$ contract with the smallest possible face value among those proposed by the bank in $\left[\overline{D^{C}}, D\right]$. If $\left(a\left(\overline{D^{C}}\right), \overline{D^{C}}\right)$ is offered by the bank, then it will be chosen by the firm. We summarize our results in Proposition 2 hereafter.

Proposition 2 Assume that a solution to Program (7)-(8) exists. Also restrict the admissible contracts to those with face value in $\left[\overline{D^{C}}, D\right]$. The firm will choose the convertible bond contract with the smallest possible face value among those offered by the bank.

This optimal strategy leads to a level of prevention $e^{*}\left(D^{C *}\right)$ which is the highest possible level among those induced by the admissible financial contracts.

Finally, issuing convertible bonds may lead to more prevention and this strategy is optimal for both the firm and the bank. Thus we expect that convertible bonds also improve the financial condition of the firm compared to straight debt. And if this property is met, convertible bonds combined with prevention still should improve the expected social welfare. Recall that it is the main objective of a regulator, who seeks to establish socially optimal environmental behaviors. These points are investigated in the following section.

\section{Solvency of the firm and social welfare}

In Subsection 3.2. we have shown that the lower face value of debt displayed by a convertible bond contract induces more internalization of the expected marginal benefit of prevention. We can also expect that, for a given amount of investment, bankruptcy has less chances to occur if borrowing becomes cheaper. Nevertheless, we have to keep in mind that prevention expenses differ depending on the nature of the financial contract. (Lemma 1 shows that prevention may increase or decrease when substituting convertible bonds for straight debt.) Prevention does affect the loss distribution and, consequently, the distribution of profits. Thus we have to cope with two effects when studying the 
impact of convertible bonds on the firm's probability of bankruptcy. In Proposition 3 hereafter we are able to conclude about the total effect.

Proposition 3 For any convertible bond contract with face value in $\left[\overline{D^{C}}, D\right]$, the firm's probability of bankruptcy is lower than that prevailing with a standard debt contract.

Proof. The probability of bankruptcy equals $1-F\left(\widehat{y}^{C} / e\right)$. We have:

$$
\frac{d\left(1-F\left(\widehat{y}^{C} / e\right)\right)}{d D^{C}}=f\left(\widehat{y}^{C} / e\right)-F_{e}\left(\widehat{y}^{C} / e\right) \frac{d e}{d D^{C}}
$$

With $F_{e}\left(\widehat{y}^{C} / e\right)$ positive and $d e / d D^{C}$ negative on $\left[\overline{D^{C}}, D[\right.$, we conclude that this derivative is always positive for any financial contract in $\left[\overline{D^{C}}, D[\right.$.

Now, we have to answer to the following important question: do the benefits for the society induced by higher levels of prevention at least counterbalance the cost of implementing these higher levels ? In other words, are convertible bonds a good way to improve the welfare of the society knowing that moral hazard and limited liability induce private sub-optimal behaviors in terms of environmental risk reduction?

When the owner-manager privately chooses the level of prevention, the expected social welfare is:

$$
\begin{aligned}
W^{C}= & (1-a) \int_{0}^{y^{C}}(X-y) f(y / e) d y+\int_{y^{C}}^{\widehat{y}^{C}}\left(X-y-D^{C}\right) f(y / e) d y-\phi(e) \\
& -\int_{X}^{T} y f(y / e) d y+X(1-F(X / e))
\end{aligned}
$$

Equation (12) is obtained by recalling that the expected net profit of the bank is nil and that victims are fully compensated up to the gross profits $X$ of the firm. The last term in (12) illustrates the fact that, for any environmental damage higher than $X$, victims receive the fixed amount $X$.

Proposition 4 In optimum, issuing convertible bonds improves the expected social welfare compared to standard debt. 


\section{Proof. See Appendix 5.}

Nevertheless, it is important to notice that convertible bonds never lead to a level of prevention equal to the optimal social one. The result is immediate when comparing the social first order condition given in Lemma 1 to the private one (9). Convertible bonds do not make it possible to internalize all the expected marginal benefit of prevention. Even if the firm's probability of being solvent increases, it looses nothing in the worst states, where the environmental damage may be very high.

Before concluding this paper with economic and managerial considerations, we invite the reader to refer to Appendix 6 for a parametrized example. We obtain a convertible bond contract that yields more prevention, a lower face value of debt and a higher expected net revenue for the bank. Besides, this contract satisfies the participation constraint of the bank, so that it belongs to the available financial contracts. And with these properties, it improves the expected social welfare compared to the standard debt contract.

\section{Discussion}

A firm whose activity is potentially risky for the environment may not choose the socially optimal level of prevention because of the moral hazard problem and partial internalization of environmental damages. Earlier studies have investigated whether the legislation CERCLA could give firms sufficient incentives to enhance environmental prevention. Actually, extended liability can, in some situations, induce still less prevention and it always generates a deterioration of the financial condition of the firm.

In this paper we have explored the economic rationale for the use of convertible bonds by such a firm. We have shown that there exist convertible debt contracts that satisfy the lender participation constraint and increase both prevention and the firm's expected welfare. Furthermore, they make it possible to increase the expected social welfare even if the actions of the manager are not perfectly observable. 
On one hand, the conversion right component gives the lender a mechanism by which he can benefit from high levels of prevention and future capital appreciation thus reducing the underinvestment problem. This implication fits well with the fact that convertible bonds may be useful when it is difficult to evaluate asset risk as reported by Brennan and Schwartz (1988). It also implies that the lender may take a more active role when monitoring the firm's expenses. On the other hand, lower interest payment involves that lower output are internalized. The manager's welfare becomes sensitive for a larger range of environmental expenses. These benefits are not outweighed by the lender's opportunity to get firm's equity because the former still has got the highest stake as specified in the optimal convertible bond contract.

Finally, it might be interesting to associate the issue of convertible bonds with a potential extended liability of banks in the refinement of the environmental legislation, rather than considering it as an alternative to extended liability. For instance, the issue of such securities could send a positive signal related to the willingness of the firm to pay for prevention. Despite the fact that banks cannot enforce firms to choose high levels of effort, they can ask them to split the funds required for their activity into debt and convertible bonds. Such a behavior could be positively interpreted by a legal court in charge of recovering funds for clean-up and compensation if an environmental damage would have occurred.

So far, we did not specify anything about the size of the firm. However, we assumed that the firm's probability to be pushed into bankruptcy by a court following an environmental damage is strictly positive. Hence, the model developed here deals more specifically with small and mediums firms for which the available assets are likely to be insufficient for comprehensive compensation. It has been shown elsewhere that convertible bonds are well suited for young and high growth firms in the context of capital venture (see for instance Gompers (1993) and Biais and Casamatta (1999)). When the activity of this kind of firms is also risky for the environment, our rationale could be an additional incentive to issue convertible bonds. 
In our one period model, it is not possible to focus on what happens if no environmental damage occurs. If those accidents may have a huge magnitude and catastrophic consequences, the probability of occurrence for a given firm is rather low. Thus, one can expect that most convertible bondholders of fast growing firms convert their bonds very quickly. Bascha and Waltz (2001) show that these securities are adequate to facilitate exit solutions through IPOs or trade sales in the venture capital industry where investors have to free capital for other investments. So, one could argue that the control of investments in prevention described in this paper is weakened since the convertible bonds are converted within a few years. However, the CERCLA legislation concerns banks. This kind of investors offer long term contracts to the firms they finance. In the case of convertible bonds, banks will ask for high conversion premium per share in order to lower the conversion probability in the first years following the issue. Moreover, even if no environmental damage occurs during several years and thus conversion become attractive, they may still have an interest to keep their convertible bonds and not to exercise their option. Control still holds. Later on, when the contract between the firm and the bank ends up, the firm may want to modify its capital structure, to invest in new activities or to diversify them, to increase its size, etc. This may motivate the issue of new convertible bonds and preventive incentives reappear.

Empirical observation shows also that most convertible bonds have embedded call option. This option gives the issuer the right to call the issue prior to the expiration date. This may force the bank to convert its bonds if an announcement of early redemption is made since the underlying share is likely to be worth much more than the redemption value. Hence, still here, we could have to cope with a problem of incentives : profits are shared between the firm and the bank and the former has no longer incentives to invest more in prevention than with standard debt. Nevertheless, the effect of the call option is mitigated by the call protection covenant which does not permit redemption in the early years.

A next step would be to sophisticate the model by introducing a second period. In 
particular, this would permit the bank to convert sequentially its bonds into shares. What would be the impact of this sequential conversion on the prevention incentives? One intuition would be to say that less prevention will be implemented because the risk neutral bank becomes the owner of part of the firm. On the other hand, more prevention can be decided if the objective of the bank is to convert in order to be able to influence the decisions taken by the manager and his team. It would also be interesting to study the optimal date(s) of conversion for the bank: is sequential conversion really optimal? One might expect that a one time conversion be the best strategy. The bank may convert all its bonds at the beginning if it wants to directly influence the decisions taken on prevention, or it could wait the end of the contract - when all random variables are realized - if the shares owned after conversion are not sufficient to enter the director board of the firm.

Appendix 1. Proof of Lemma 1.

Differentiation with respect to (w.r.t.) $e$ of the firm's expected net revenue (2) yields the following first order condition:

$$
\int_{0}^{\widehat{y}(D)}(X-y-D) f_{e}\left(y / e^{P}\right) d y=\phi^{\prime}\left(e^{P}\right)
$$

Knowing that $F_{e}(0 / e)=0$ and $X-D-\widehat{y}=0$, integration by part of the left-hand-side term w.r.t. $y$ leads to:

$$
e^{P} \text { is such that } \int_{0}^{\widehat{y}(D)} F_{e}\left(y / e^{P}\right) d y=\phi^{\prime}\left(e^{P}\right)
$$

A second differentiation of this first order condition yields $R_{e e}=\int_{0}^{\widehat{y}(D)} F_{e e}\left(y / e^{P}\right) d y-$ $\phi^{\prime \prime}\left(e^{P}\right)$, which is negative, so that the second order condition is satisfied.

In the same manner, differentiation of (3) yields the expression $\int_{0}^{T}(X-y) f_{e}\left(y / e^{S}\right) d y=$ $\phi^{\prime}\left(e^{S}\right)$. With $F_{e}(0 / e)=F_{e}(T / e)=0$ and an integration by part, we obtain that $e^{S}$ is such that $\int_{0}^{T} F_{e}\left(y / e^{S}\right) d y=\phi^{\prime}\left(e^{S}\right)$. Here again, the second order conditions are satisfied. 
Appendix 2. Proofs related to Section 2.

To show the impact of extended liability on the level of prevention, we have to compute $\frac{d e}{d l}=\frac{d e}{d D} \cdot \frac{d D}{d l}$. This is done in two steps, with the unambiguous notation $e^{P} \equiv e$. First, we obtain the following relation thanks to a total differentiation of the private first order condition given in Lemma 1, with $\widehat{y}(D)=X-D$ :

$$
\frac{d e}{d D}=-\frac{F_{e}(\widehat{y}(D) / e)}{\left|R_{e e}\right|}<0
$$

The firm always decreases the level of prevention when borrowing becomes more costly. Besides, total differentiation of the participation constraint (1) of the bank w.r.t. $D$ and to $l$ leads to

$$
\frac{d D}{d l}=\frac{1-F(X+l / e)}{F(\widehat{y}(D) / e)}>0 \text { for any } l \text { in }[0, T-X[
$$

The bank always increases the cost of borrowing if it may be held liable for an environmental damage. Equations (13) and (14) make it possible to conclude that extended liability always leads to a lower private level of prevention than standard debt without extended liability. Furthermore, it always deteriorates the financial condition of the firm. Indeed, with $(1-F(\widehat{y}(D) / e)$ the firm's probability of bankruptcy and $\widehat{y}=X-D$ we get

$$
\frac{d(1-F(\widehat{y}(D) / e))}{d l}=\left(f(\widehat{y}(D) / e)-F_{e}(\widehat{y}(D) / e) \cdot \frac{d e}{d D}\right) \cdot \frac{d D}{d l}>0
$$

Appendix 3. Proof of Lemma 2.

With $F_{e}(0 / e)=0$ and $X-D^{C}-\widehat{y}^{C}=0$, differentiation of (7) w.r.t. $e$ and integrations by part yield:

$$
\begin{aligned}
& \phi^{\prime}\left(e^{*}\right)=(1-a) \int_{0}^{y^{C}}(X-y) f_{e}\left(y / e^{*}\right) d y+\int_{y^{C}}^{\widehat{y}^{C}}\left(X-y-D^{C}\right) f_{e}\left(y / e^{*}\right) d y \\
& \Leftrightarrow \phi^{\prime}\left(e^{*}\right)=(1-a)\left(X-y^{C}\right) F_{e}\left(y^{C} / e^{*}\right)-\left(X-y^{C}-D^{C}\right) F_{e}\left(y^{C} / e^{*}\right) \\
& +(1-a) \int_{0}^{y^{C}} F_{e}\left(y / e^{*}\right) d y+\int_{y^{C}}^{\hat{y}^{C}} F_{e}\left(y / e^{*}\right) d y
\end{aligned}
$$


Recall that $(1-a)\left(X-y^{C}\right)=\left(X-y-D^{C}\right)$. We obtain finally:

$$
(1-a) \int_{0}^{y^{C}} F_{e}\left(y / e^{*}\right) d y+\int_{y^{C}}^{\widehat{y}^{C}} F_{e}\left(y / e^{*}\right) d y=\phi^{\prime}\left(e^{*}\right)
$$

Lemma 2 is demonstrated.

\section{Appendix 4. Proof of Proposition 1.}

Since, in our simple model, a CB contract can be completely defined by the value of $D^{C}$ (with $a \equiv a\left(D^{C}\right)$ ) and because a $\mathrm{CB}$ contract displays a lower face value than standard debt, we have to focus on the variation of prevention following a decrease in the face value of debt. Thanks to a total differentiation of the private first order condition (9), we have:

$$
R_{e e^{C}}^{C} \cdot d e+\left(R_{e y}^{C} \cdot y_{D^{C}}^{C}+R_{e \widehat{y}^{C}}^{C} \cdot \widehat{y}_{D^{C}}^{C}+R_{e a}^{C} \cdot a^{\prime}\left(D^{C}\right)+R_{e D^{C}}^{C}\right) \cdot d D^{C}=0
$$

With $\widehat{y}^{C}$ defined by (6) and $y^{C}$ defined by (5), we get:

$$
\begin{aligned}
\frac{d e}{d D^{C}} & =\frac{(1-a) F_{e}\left(y^{C} / e\right)\left(\frac{D^{C} a^{\prime}}{a^{2}}-\frac{1}{a}\right)-F_{e}\left(y^{C} / e\right)\left(\frac{D^{C} a^{\prime}}{a^{2}}-\frac{1}{a}\right)-F_{e}\left(\widehat{y}^{C} / e\right)-a^{\prime}\left(D^{C}\right) \int_{0}^{y^{C}} F_{e}(y / e) d y}{-R_{e e}^{C}} \\
& \Leftrightarrow \frac{d e}{d D^{C}}=\frac{-F_{e}\left(y^{C} / e\right)\left(\frac{D^{C} a^{\prime}}{a}-1\right)-F_{e}\left(\widehat{y}^{C} / e\right)-a^{\prime}\left(D^{C}\right) \int_{0}^{y^{C}} F_{e}(y / e) d y}{-R_{e e}^{C}} \\
\Leftrightarrow \frac{d e}{d D^{C}}=\frac{-\left(F_{e}\left(\widehat{y}^{C} / e\right)-F_{e}\left(y^{C} / e\right)\right)-a^{\prime}\left(D^{C}\right)\left(F_{e}\left(y^{C} / e\right) \frac{D^{C}}{a}+\int_{0}^{y^{C}} F_{e}(y / e) d y\right)}{-R_{e e}^{C}} & \\
\Leftrightarrow \frac{d e}{d D^{C}}= & \frac{\left(F_{e}\left(\widehat{y}^{C} / e\right)-F_{e}\left(y^{C} / e\right)\right)+a^{\prime}\left(D^{C}\right)\left(F_{e}\left(y^{C} / e\right) \frac{D^{C}}{a}+\int_{0}^{y^{C}} F_{e}(y / e) d y\right)}{R_{e e}^{C}}
\end{aligned}
$$

The denominator of $d e / d D^{C}$ is negative, while the sign of the numerator is undetermined. Nevertheless, more can be said by focusing on the limits of the ratio. We have: 


$$
\lim _{D^{C} \uparrow D} \frac{d e}{d D^{C}}=\frac{F_{e}(\widehat{y} / e)}{R_{e e}^{C}}<0
$$

This result is obtained because $y^{C}$ tends towards 0 and $\widehat{y}^{C}$ towards $\widehat{y}$ (defined in Section 2) when $D^{C}$ gets closer to $D$. We also have:

$$
\lim _{D^{C} \downarrow 0} \frac{d e}{d D^{C}}=\frac{a^{\prime}\left(D^{C}\right) \int_{0}^{X} F_{e}(y / e) d y}{R_{e e}^{C}}>0
$$

This result is due to the fact that $y^{C}$ and $\widehat{y}^{C}$ tend towards $X$ as $D^{C}$ gets closer to zero. Since $d e / d D^{C}$ is continuous in $D^{C}$, it exists a level $\overline{D^{C}}$ strictly smaller than $D$, such that $d e / d D^{C}$ is negative for any $D^{C}$ in $] \overline{D^{C}}, D\left[\right.$ and such that $\left.\frac{d e}{d D^{C}}\right|_{D^{C}=\overline{D^{C}}}=0$. Proposition 1 is demonstrated.

\section{Appendix 5. Proof of Proposition 4.}

It is sufficient to show that the expected social welfare increases as the face value of debt decreases when starting from $D$ on. The total derivative with respect to $D^{C}$ of $W^{S}$, defined by (12), gives

$$
\begin{gathered}
\frac{d W^{S}}{d D^{C}}=W_{D^{C}}^{S}+W_{e}^{S} \cdot \frac{d e}{d D^{C}}+W_{y^{C}}^{S} \cdot y_{D^{C}}^{C}+W_{\widehat{y}^{C}}^{S} \cdot \widehat{y}_{D^{C}}^{C}+W_{a}^{S} \cdot a^{\prime}\left(D^{C}\right) \\
\Leftrightarrow \frac{d W^{S}}{d D^{C}}=-\int_{y^{C}}^{\widehat{y}^{C}} f(y / e) d y+\frac{d e}{d D^{C}}\left[-\int_{X}^{T} y f_{e}(y / e) d y-(X) F_{e}(X / e)\right] \\
+(1-a) \frac{D^{C}}{a}\left(\frac{D^{C} \cdot a^{\prime}}{a^{2}}-\frac{1}{a}\right) f\left(y^{C} / e\right)-(1-a) \frac{D^{C}}{a}\left(\frac{D^{C} \cdot a^{\prime}}{a^{2}}-\frac{1}{a}\right) f\left(y^{C} / e\right) \\
\Leftrightarrow \frac{a^{\prime} \int_{0}^{C}(X-y) f(y / e) d y}{\Leftrightarrow \frac{d W^{S}}{d D^{C}}}=\frac{d e}{d D^{C}}\left[\int_{X}^{T} F_{e}(y / e) d y\right]-\left(F\left(\widehat{y}^{C} / e\right)-F\left(y^{C} / e\right)+a^{\prime} \int_{0}^{y^{C}}(X-y) f(y / e) d y\right)
\end{gathered}
$$


The sign of (18) is undetermined. But it is possible to conclude when focusing on the interval where $d e / d D^{C}$ is negative, namely on $\left[\overline{D^{C}}, D[\right.$. Indeed, notice that the second expression in the right-hand-side term of (18) corresponds to minus $d R^{C} / d D^{C}$, defined in Point i) of Lemma 3. It is positive or equal to zero when evaluated on $\left[\overline{D^{C}}, D[\right.$ (this was discussed in the text). With $d e / d D^{C}$ negative on $\left[\overline{D^{C}}, D\left[\right.\right.$, we obtain that $\frac{d W^{S}}{d D^{C}}$ is always negative for any contract in $\left[\overline{D^{C}}, D[\right.$. Proposition 4 is demonstrated.

Appendix 6. Computations for the parametrized example.

Computations have been made with Maple V Release 2. The detailed computation can be obtained upon request to the authors.

In the first paragraph here, we focus on the standard debt model. Then we present the results obtained with convertible bonds. We show that, from one model to the other, prevention increases, the face value of debt decreases, the participation constraint of the bank is satisfied, the expected net revenue of the firm is improved and, finally,the expected social welfare is also improved. For both models, we use a distribution function given by LiCalzi and Spaeter (2002). It satisfies the properties needed in many issues of asymmetric information and, in particular, those assumed for our modelization. Still we assume the following parameters as given :

$X=10$ (gross profits)

$y \in[0,15]$ (environmental risk)

$e \in[0 ; 5,4]$ (level of prevention)

$B=2$ (external funds)

$i=0$ (the risk free interest rate is normalized to zero without loss of generality)

$l=0$ (no extended liability)

$\phi(e)=0,01 e^{2}$ (the opportunity cost of prevention)

The distribution $F$ of the environmental risk is defined as

$$
F(y / e)=\left[\frac{(e+1)^{1 / 2}}{k}(T-y)+1\right] \cdot \frac{y}{T}, \text { with } y \text { in }[0, T],
$$


which implies that

$$
f(y / e)=\left[\frac{(e+1)^{1 / 2}}{k}(T-2 y)+1\right] \cdot \frac{1}{T} .
$$

The parameter $k$ must be such that the density function is well defined. Since $e$ takes values in $[0 ; 5,4]$ in this parametrization, it is sufficient to assume that $k=38$.

\subsection{Standard debt}

With the parameters defined just above, Equ. (2) and (1) of the maximization program become:

$$
\begin{aligned}
\max _{e, D} R= & \int_{0}^{10-D}(10-y-D)\left[\frac{(e+1)^{1 / 2}}{45}(15-2 y)+1\right] \cdot \frac{1}{15} d y-0,01 e^{2} \\
& \text { subject to } \\
& 2-D\left[\frac{(e+1)^{1 / 2}}{45}(15-(10-D))+1\right] \cdot \frac{(10-D)}{15} \\
& -\int_{10-D}^{10}(10-y)\left[\frac{(e+1)^{1 / 2}}{45}(15-2 y)+1\right] \cdot \frac{1}{15} d y=0
\end{aligned}
$$

The expected social welfare obtained when the manager privately chooses his level of prevention is:

$$
W=R-\int_{X}^{T} y f(y / e) d y+X(1-F(X / e))
$$

Explanations of each term of $W$ are similar to those proposed for $W^{C}$ in the text (Equ. (12)). With our parameters, we have:

$$
\begin{aligned}
W= & R-\int_{10}^{15} y\left[\left(\frac{(e+1)^{1 / 2}}{45}(15-2 y)+1\right) \cdot \frac{1}{15}\right] d y \\
& +10\left(1-\left[\frac{(e+1)^{1 / 2}}{45}(15-10)+1\right] \cdot \frac{10}{15}\right)
\end{aligned}
$$

Computations lead to:

$$
\begin{gathered}
e^{P}=5,0667 \\
D=2,4416
\end{gathered}
$$


$R\left(e^{P}, D\right)=2,8771$

$W\left(e^{P}, D\right)=2,6740$.

\subsection{Convertible bonds}

For the computations we use the notation $D^{C} \equiv d$. The maximization program (7)-(8) becomes:

$$
\begin{aligned}
\max _{e, d} R^{C}= & (1-a) \int_{0}^{10-d / a}(10-y)\left[\frac{(e+1)^{1 / 2}}{45}(15-2 y)+1\right] \cdot \frac{1}{15} d y \\
& +\int_{10-d / a}^{10-d}(10-y-d)\left[\frac{(e+1)^{1 / 2}}{45}(15-2 y)+1\right] \cdot \frac{1}{15} d y-0,01 e^{2} \\
\text { subject to } & \left(2-a \int_{0}^{10-d / a}(10-y)\left[\frac{(e+1)^{1 / 2}}{45}(15-2 y)+1\right] \cdot \frac{1}{15} d y\right. \\
& -d\left(\left[\frac{(e+1)^{1 / 2}}{45}(15-(10-d))+1\right] \cdot \frac{(10-d)}{15}\right. \\
& \left.-\left[\frac{(e+1)^{1 / 2}}{45}(15-(10-d / a))+1\right] \cdot \frac{(10-d / a)}{15}\right) \\
& -\int_{10-d}^{10}(10-y)\left[\frac{(e+1)^{1 / 2}}{45}(15-2 y)+1\right] \cdot \frac{1}{15} d y=0
\end{aligned}
$$

The expected social welfare $W^{C}$ when $e^{*}$ is privately chosen, defined by (12), can be rewritten:

$$
\begin{aligned}
W^{C}= & R^{C}-\int_{10}^{15} y\left[\left(\frac{(e+1)^{1 / 2}}{45}(15-2 y)+1\right) \cdot \frac{1}{15}\right] d y \\
& +10\left(1-\left[\frac{(e+1)^{1 / 2}}{45}(15-10)+1\right] \cdot \frac{10}{15}\right)
\end{aligned}
$$

Recall that the parameter $a$ is a percentage with values in $[0,1]$, which is decreasing in $d$. For sake of simplicity, we assume that the relation between $a$ and $d$ is linear and defined as follows: $a(d)=1-\frac{d}{D}$. With $D=2,4416$ obtained with the previous computation, $a(d)$ equals $1-\frac{d}{2,4416}$. Now computations lead to:

$$
\begin{aligned}
& e^{*}=5,1136 \\
& d=2,1001
\end{aligned}
$$




$$
\begin{aligned}
& R^{C}\left(e^{*}, d\right)=2,8793 \\
& W^{C}\left(e^{*}, d\right)=2,6786 .
\end{aligned}
$$

By comparing these results with those obtained just above, we conclude that there exists a convertible bond contract that yields more prevention $\left(e^{*}>e^{P}\right)$, a lower face value of debt $(d<D)$ and a higher expected net revenue for the firm $\left(R^{C}>R\right)$. Besides, such a contract $(a, D)$ satisfies the participation constraint of the bank so that it belongs to the available contracts. It also improves the expected social welfare $\left(W^{C}>W\right)$.

\section{References}

[1] Anderson D.R., (1998), "Development of Environmental Liability Risk Management and Insurance in the United States : Lessons and Opportunities", Risk Management and Insurance Review 2, 1-23.

[2] Barnea A., R. Haugen and L. Senbet, (1980), "A Rationale for Debt Maturity Structure and Call Provisions in the Agency Theoretic Framework", The Journal of Finance 35, 1223-34.

[3] Bascha A. and U. Walz, (2001), "Convertible Securities and Optimal Exit Decisions in Venture Capital Finance", Journal of Corporate Finance 7, 285-306.

[4] Beard T.R., (1990), "Bankruptcy and Care Choice", Rand Journal of Economics 21, 626-34.

[5] Biais B. and C. Casamatta, (1999), "Optimal Leverage and Aggregate Investment", The Journal of Finance 54, 1291 - 1323.

[6] Boyer M. and J.J. Laffont, (1996), "Environmental Protection, Producer Insolvency and Lender Liability", in Xepapadeas A. (Ed.), Economic Policy for the Environment and Natural Resources, Edward Elgar, Cheltenham, UK, 1996, 1-29.

[7] Boyer M. and J.J. Laffont, (1997), "Environmental Risks and Bank Liability", European Economic Review 41, 1427-59. 
[8] Brennan M. and E. Schwartz, (1988), "The Case for Convertibles", Journal of Applied Corporate Finance 1, 55-64.

[9] Brigham E., (1966), "An Analysis of Convertible Debentures: Theory and some Empirical Evidence", The Journal of Finance 21, 35-54.

[10] Calcagno R., (2001), "Is Leverage Effective in Increasing Performance under Managerial Moral Hazard?", CenTER Discussion Paper, Tilburg University.

[11] Chiesa G., (1992), "Debts and Warrants: Agency Problems and Mechanism Design", Journal of Financial Intermediation 2, 237-54.

[12] Coestier B., (2000), "Dynamic Financial Contract under Extended Liability", Working paper 00-08, Risk Management Chair, HEC-Montreal.

[13] Dionne G. and S. Spaeter, (2002), "Environmental Risks and Extended Liability: The Case of Green Technologies", forthcoming in Journal of Public Economics.

[14] Dionne G. and P. Viala, (1994), "Moral Hazard, Renegotiation and Debt", Economics letters 46, 113-9.

[15] Essig. J., (1991), "Convertible Securities and Capital Structure Determinants", PhD Dissertation, Graduate School of Business, University of Chicago.

[16] European Environmental Bureau, (1998), "Environmental liability in Europe: Concerning the need for a European Directive on environmental liability", at www.eeb.org/archive/archive.htm.

[17] Gobert K. and M. Poitevin, (1998), "Environmental Risks: Should Banks be Liable?", Working Paper 98-2, Cirano-Chaire Jarislowsky, Université de Montréal.

[18] Gompers P.A., (1993), "The Theory, Structure and Performance of Venture Capital", PhD Dissertation, Harward University, Cambridge, MA. 
[19] Green R., (1984), "Investment Incentives, Debt and Warrants", Journal of Financial Economics 13, 115-36.

[20] Hoffmeister R., (1977), "Use of Convertible Debt in the Early 1970s: a Reevaluation of Corporations Motives", Quarterly Review of Economics and Business 17, 21-31.

[21] Innes R.T., (1990), "Limited Liability and Incentive Contracting with ex-ante Action Choices", Journal of Economic Theory 52, 45-67.

[22] LiCalzi M. and S. Spaeter, (2002), "Distributions for the First-Order Approach to Principal-Agent Problems", forthcoming in Economic Theory.

[23] Lipowsky-Posey L., (1993), "Limited Liability and Incentives when Firms Can Inflict Damages Greater than Net Worth", International Review of Law and Economics 13, 325-30.

[24] Pitchford R., (1995), "How Liable Should a Lender Be? The Case of JudgmentProof Firms and Environmental Risks", American Economic Review 85, 1171-86.

[25] Robe M.A., (1999), "Optimal vs. Traditional Securities under Moral Hazard", Journal of Financial and Quantitative Analysis 34, 161-89.

[26] Robe M.A., (2002), "Harsh Default Penalties or Warrants: The Impact of Limited Liability Rules", Working Paper 01-12_01, Kogol School of Business at American University.

[27] Sappington D., (1983), "Limited Liability Contracts between Principal and Agent", Journal of Economic Theory 29, 1-21.

[28] Smets H., (1992), "L'indemnisation complète des victimes de la pollution accidentelle", Risques 11, 49-71.

[29] Stein J., (1992), "Convertible Bonds as Backdoor Equity Financing", Journal of Financial Economics 32, 3-21. 
Manager's revenue

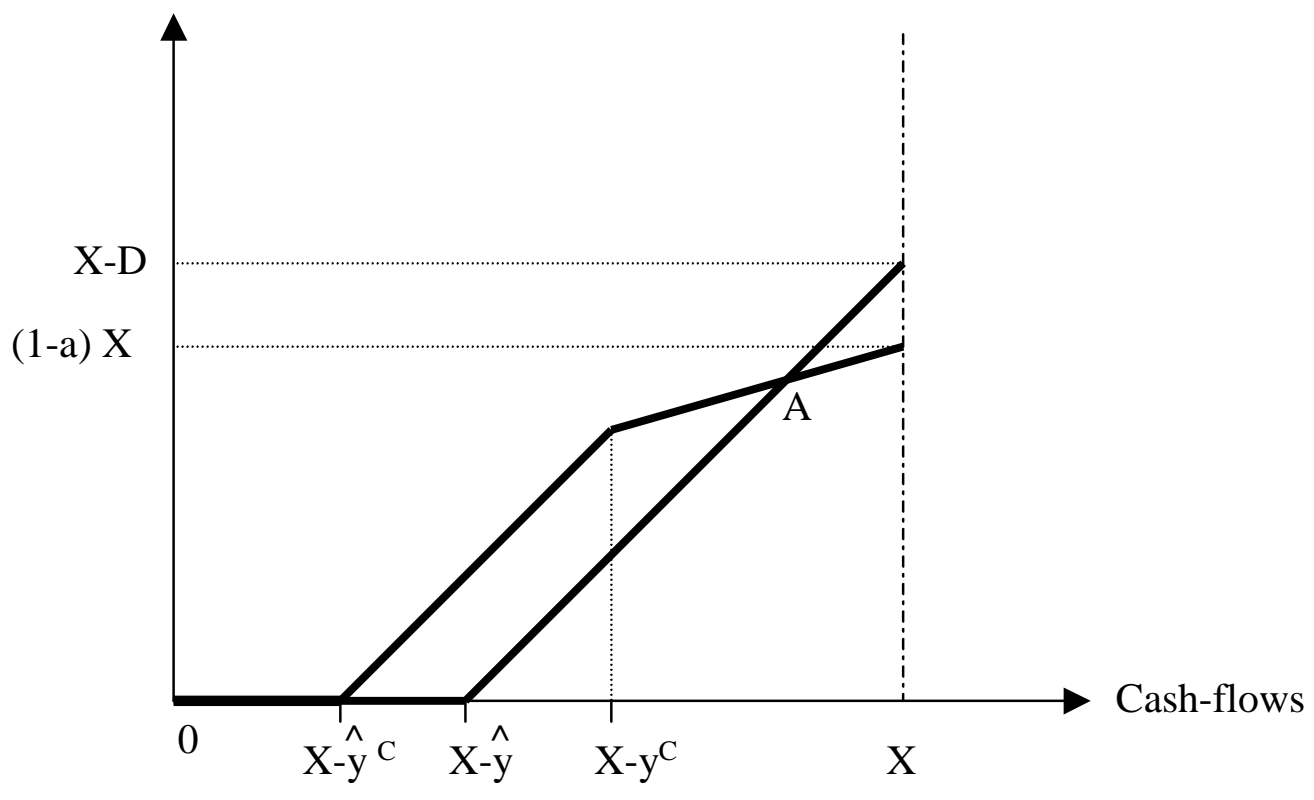

Figure 1. Straight debt and convertible bond 